\title{
Construction and integrated analysis of crosstalking ceRNAs networks in laryngeal squamous cell carcinoma
}

\author{
Yuehui Liu ${ }^{\text {Corresp., }}$, Fan Ye ${ }^{1}$ \\ ${ }^{1}$ Department of Otorhinolaryngology Head and Neck Surgery, The Second Affiliated Hospital of Nanchang University, Nanchang, Jiangxi Province, People's \\ Republic of China \\ Corresponding Author: Yuehui Liu \\ Email address: 02001@mail.jxndefy.cn
}

Background: Laryngeal squamous cell carcinoma (LSCC) is one of the most common malignant tumours of the head and neck. Recent evidence has demonstrated that IncRNAs play important roles in tumour progression and could be used as biomarkers for early diagnosis, prognosis, and potential therapeutic targets. The "competitive endogenous RNA (ceRNA)" hypothesis states that IncRNAs competitively bind to miRNAs through their intramolecular miRNA reaction elements (MREs) to construct a wide range of ceRNA regulatory networks. This study aims to predict the role of ceRNA network in LSCC, for advancing the understanding of underlying mechanisms of tumorigenesis.

Material and Methods: In this study, the functions of IncRNAs as ceRNAs in LSCC and their prognostic significance were investigated via comprehensive integrated expression profiles data of IncRNAs, mRNAs, and miRNAs obtained from The Cancer Genome Atlas (TCGA). Protein-protein interaction, gene ontology, pathway, and Kaplan-Meier curves analysis were used to profile the expression and function of altered RNAs in LSCC

Results: As a result, 889 IncRNAs, 55 miRNAs and 1946 mRNAs were found to be differentially expressed in LSCC. These altered mRNAs were mainly involved in extracellular matrix organization, calcium signaling, and metabolic pathways. To study the regulatory function of IncRNAs, an IncRNAmediated ceRNA network was constructed. This ceRNA network included 61 IncRNAs, 7 miRNAs and 7 target mRNAs. Of these RNAs, IncRNAs (TSPEAR-AS, CASK-AS1, MIR137HG, PART1, LSAMP-AS1), miRNA (has-mir-210) and mRNAs (HOXC13, STC2, DIO1, FOXD4L1) had a significant effect on the prognosis of LSCC.

Conclusion: The results of this study broaden the understanding of the mechanisms by which IncRNAs are involved in tumorigenesis. Furthermore, five IncRNAs (TSPEAR-AS $\square$ CASK-AS1, MIR137HG, PART1, LSAMP-AS1) were identified as potential prognostic biomarkers and therapeutic targets for LSCC. These results provide a basis for further experimental and clinical research. 


\section{Construction and integrated analysis of crosstalking}

3 ceRNAs networks in laryngeal squamous cell

4 carcinoma

5

6

7

8

9

10

11

12

13

14

15

Yuehui Liu ${ }^{1}$, Fan $\mathrm{Ye}^{2}$

${ }^{1}$ Department of Otorhinolaryngology Head and Neck Surgery, The Second Affiliated Hospital of Nanchang University, Nanchang, Jiangxi Province, People's Republic of China

${ }^{2}$ Department of Otorhinolaryngology Head and Neck Surgery, The Second Affiliated Hospital of Nanchang University, Nanchang, Jiangxi Province, People's Republic of China

Corresponding Author:

Yuehui Liu ${ }^{1}$

Mingde Road ,Nanchang 330006, Jiangxi Province, People's Republic of China

Email address:02001@mail.jxndefy.cn

\section{Abstract}

Background: Laryngeal squamous cell carcinoma (LSCC) is one of the most common malignant tumours of the head and neck. Recent evidence has demonstrated that lncRNAs play important roles in tumour progression and could be used as biomarkers for early diagnosis, prognosis, and potential therapeutic targets. The "competitive endogenous RNA (ceRNA)" hypothesis states that lncRNAs competitively bind to miRNAs through their intramolecular miRNA reaction elements (MREs) to construct a wide range of ceRNA regulatory networks. This study aims to predict the role of ceRNA network in LSCC, for advancing the understanding of underlying mechanisms of tumorigenesis.

Material and Methods: In this study, the functions of lncRNAs as ceRNAs in LSCC and their prognostic significance were investigated via comprehensive integrated expression profiles data of lncRNAs, mRNAs, and miRNAs obtained from The Cancer Genome Atlas (TCGA). Proteinprotein interaction, gene ontology, pathway, and Kaplan-Meier curves analysis were used to profile the expression and function of altered RNAs in LSCC

Results: As a result, 889 lncRNAs, 55 miRNAs and 1946 mRNAs were found to be differentially expressed in LSCC. These altered mRNAs were mainly involved in extracellular matrix organization, calcium signaling, and metabolic pathways. To study the regulatory function of lncRNAs, an lncRNA-mediated ceRNA network was constructed. This ceRNA network included 61 lncRNAs, 7 miRNAs and 7 target mRNAs. Of these RNAs, IncRNAs (TSPEAR-AS, CASK-AS1, MIR137HG, PART1, LSAMP-AS1), miRNA (has-mir- 
210) and mRNAs (HOXC13, STC2, DIO1, FOXD4L1) had a significant effect on the prognosis of LSCC.

Conclusion: The results of this study broaden the understanding of the mechanisms by which lncRNAs are involved in tumorigenesis. Furthermore, five lncRNAs (TSPEAR-AS, CASKAS1, MIR137HG, PART1, LSAMP-AS1) were identified as potential prognostic biomarkers and therapeutic targets for LSCC. These results provide a basis for further experimental and clinical research. MeSH Keywords: Laryngeal Neoplasms, RNA, Long Noncoding, MicroRNAs

\section{Introduction}

Laryngeal squamous cell carcinoma (LSCC) is considered to be one of the most common malignant tumors of the head and neck. It is estimated that 13,150 new cases of laryngeal cancer were diagnosed in the United States in 2018, of which about 3,710 patients died(Siegel et al. 2018). Approximately $60 \%$ of the patients were diagnosed with advanced (stage III or IV) cancer(Groome et al. 2003). Although there has been great progress in the treatment of laryngeal cancer, the survival rate in the past few decades is still very low, and has been exhibiting a downward trend(Steuer et al. 2017; Wan et al. 2010). These reports highlight the necessity for more research and innovation in this area.

Long non-coding RNA (LncRNAs), composed of $>200$ nucleotides (nt) without proteincoding ability, have been found to function at epigenetic, transcriptional, post-transcriptional and translational levels (Khorkova et al. 2015). Recent evidence has demonstrated that lncRNAs play important roles in tumor progression and could serve as biomarkers for early diagnosis, prognosis and potential therapeutic targets of various cancers (Gong et al. 2014; Parasramka et al. 2016; Rupaimoole et al. 2015; Yuan et al. 2014). Although more than 50,000 lncRNA genes have been cloned and identified in the human genome, only a small part of their biological functions have been verified experimentally. Therefore, more efforts should be dedicated towards revealing how lncRNAs play multiple biological functions in malignant tumors. As described in the "competitive endogenous RNA(ceRNA)" hypothesis, IncRNAs competitively bind to miRNAs through their intramolecular miRNA reaction elements (MREs) to construct a wide range of ceRNA regulatory networks(Salmena et al. 2011). Specifically, lncRNAs acting as endogenous miRNA sponge competitively bind to a limited pool of miRNAs, affecting the inhibition of miRNAs on target genes. In fact, miRNA, a non-coding RNA of approximately 22 nucleotides in length, has been found to play an important role in tumorigenesis (BerindanNeagoe et al. 2014; Di Leva et al. 2014; McGuire et al. 2015; Shin \& Chu 2014). MiRNAs interact with Argonaute (AGO) and other proteins to form RNA-induced silencing complexes that bind to 3'UTRs of target RNAs to degrade target RNA or prevent translation(Di Leva et al. 2014). Studies have shown that one miRNA can inhibit hundreds of transcripts, while one lncRNA can inhibit multiple miRNAs (Friedman et al. 2009; Salmena et al. 2011). These data indicate that there is a large and complex ceRNA regulatory network in cells. 
It is now well established from a variety of studies that competitive binding of lncRNA to miRNA plays an important role in the development of LSCC. For instance, the overexpression of RP11-169D4.1, which is a target of miR-205-5p, inhibits the proliferation, migration, and invasion of LSCC cell lines as well as promotes apoptosis (Zhao et al. 2017). NEAT1 is a novel target of miR-107 which can stimulate the invasion and metastasis of LSCC through regulating miR-107/CDK6 pathway (Wang et al. 2016b). AFAP1-AS1 increases RBPJ expression by negatively regulating miR-320a, and prevents drug resistance of LSCC (Yuan et al. 2018). Currently, ceRNA mechanism is the most interesting in lncRNA-mediated tumorigenesis. Therefore, this work aims to predict the role of ceRNA network in LSCC, for advancing the understanding of the underlying mechanisms for tumorigenesis.

The Cancer Genome Atlas（TCGA）, which provides normalized transcriptome profiling data, has increased understanding of the genetic basis of cancer. In this study, a comprehensive analysis of transcriptome data of LSCC from TCGA was performed. Significantly differentially expressed lncRNAs, miRNAs and mRNAs were identified in LSCC through comparing transcriptome data between tumor and normal tissues. Further, the biological functions of aberrantly expressed mRNAs and miRNA were explored via DAVID, KOBAS and Cytoscape plug-ins (ClueGO, CluePedia). A ceRNA network was then established based on the miRNA-binding site on both lncRNAs and mRNAs. To establish reliable biological markers for LSCC, survival analysis on RNA in ceRNA networks was finally performed through the corresponding clinical information from TCGA. The findings of this study provide new insight into the potential regulatory roles of the identified RNAs and how they affect LSCC pathogenesis.

\section{Materials \& Methods}

\section{Study population}

In this study, a comprehensive analysis of RNA-Seq data and clinical information of LSCC from the TCGA database was conducted. To realize this goal, a comprehensive search was firstly conducted in TCGA based on the following criteria: (Disease Type is Squamous Cell Neoplasms ), (Primary Site is Larynx), (Program Name is TCGA) , (Workflow Type is HTSeq-Counts), (Data Category is Transcriptome Profiling) and (Data Type is Gene Expression Quantification). The RNA-Seq data was then downloaded through a data transfer tool provided by TCGA. Finally, the RNA-Seq data of 111 tumor samples and 12 normal samples, and their corresponding clinical information was obtained. In addition, miRNA-Seq data specially used for analyzing differentially expressed miRNAs was downloaded. These 
116 miRNA-Seq data were obtained from 117 tumor samples and 12 normal samples. Detailed

117 characteristics of the patients are shown in Table 1. (Table 1)

118 Differentially expressed analysis of RNAs

119 The RNA-seq data was downloaded, after which the expression analysis of lncRNA, mRNA, and

120

121

122

123

124

125

126

127

128

129

130

131

132

133

134

135

136

137

138

139

140

141

142

143

144

145

146

147

148

149

150

151

152

153

154 miRNA was performed. Based on previously reported methods (Huang et al. 2017), the different expression of RNAs between larynx cancer and normal tissues was evaluated using the "edgeR" package in R software with thresholds of $\mid \log 2$ foldChange(FC) $\mid>2.0$ and adjusted Pvalue $<0.01$. Volcano maps were then drawn to generate a graphical overview of their expression profile via "gplots" package in R software.

\section{Construct the ceRNA network}

In the current study, the interaction of IncRNA-miRNA-mRNA was predicted in LSCC based on the overlapping of the miRNA seed sequence binding site on both lncRNAs and mRNAs. The interaction between abnormally expressed lncRNAs and miRNAs was firstly predicted through Mircode database which provides "whole transcriptome" human miRNA target predictions based on the comprehensive GENCODE gene annotation and includes $>10,000$ long non-coding RNA genes. The miRTarBase, TargetScan, and miRDB databases were then used to identify aberrantly expressed miRNA-mRNA pairs. This study included the target mRNAs which matched the databases only. Finally, lncRNA-miRNA and miRNA-mRNA pairs were merged into a ceRNA network based on their shared miRNAs. The Cytoscape v3.6.1 software was used to visualize the co-expression network of differentially expressed mRNAs, lncRNAs and miRNAs.

\section{Protein-protein interaction analysis}

To study the protein-protein interaction (PPI) in LSCC, String (Search Tool for the Retrieval of Interacting Genes) online tools were used to construct a PPI network for significantly aberrant mRNAs. In brief, the list of top 500 abnormally expressed mRNAs were uploaded to String for analysis. The minimum required interaction score was set at 0.7 , meaning that the association between proteins had high confidence. Cytoscape plug-in CentiScape was then used to analyze the PPI network and screen out its hub proteins. Finally, Cytoscape software was used to visualize the PPI networks.

\section{Functional \& pathway enrichment analyses}

Significantly aberrantly expressed mRNAs were used to conduct gene ontology (GO) and Kyoto Encyclopedia of Genes and Genomes (KEGG) pathway analysis via DAVID 6.8 and KOBAS 3.0 respectively. GO and pathway annotation networks was then established using Cytoscape plug-in ClueGO as described by Bindea et al.(Bindea et al. 2009). The primary parameters used were as follows: showing only pathways with $\mathrm{p}<0.05$; GO term or pathway network connectivity $(\kappa$-score $)=0.4$. In order to identify the function of differentially expressed miRNAs in laryngeal cancer, GO and KEGG enrichment were indirectly performed through their target genes. To this end, the target mRNAs were firstly predicted using CluePedia, a Cytoscape plugin. Using ClueGO, bio-process and pathway analysis of these target mRNAs were then 
155

156

157

158

159

160

161

162

163

164

165

166

167

168

169

170

171

172

173

174

175

176

177

178

179

180

181

182

183

184

185

186

187

188

189

190

191

192

performed. To visualize the function of these miRNAs, miRNA-mRNA pairs and functional items were correlated and presented through Cytoscape.

\section{Survival analysis}

To analyze the prognostic significance of differentially expressed RNAs in ceRNA network, survival analysis was conducted using clinical information from TCGA. As previously described (Huang et al. 2017), this study was based on Kaplan-Meier curve analysis. The survival curve was plotted using the "survival" package in $\mathrm{R}$ with the cutoff of $\mathrm{p}<0.05$.

\section{Results}

\section{Differentially expressed IncRNAs and mRNAs in LSCC}

Gene expression quantification data of 111 cancer samples and 12 normal samples were downloaded via a data transfer tool provided by TCGA. IncRNAs and mRNAs were then extracted from the gene expression quantification data using computer script for differential analysis. Consequently, 889 lncRNAs and 1946 mRNAs were found to be aberrantly expressed, through the "edgeR" package in R software with thresholds of $\mid \log 2$ foldChange (FC) $\mid>2.0$ and adjusted P-value $<0.01$. Of these RNAs, $617 \mathrm{lncRNAs}$ and 1008 mRNAs were upregulated, while 272 lncRNAs and 936 mRNAs were downregulated. The top 30 of aberrantly expressed lncRNAs and mRNAs were presented in tables ranked in order of $\mid \log 2$ foldChange (FC)| (Tables 2 and 3 ). To visually describe these differentially expressed lncRNAs and mRNAs between LSCC and normal group, their expression profiles were presented using volcano maps (Figures 1A, B). The "gplots" package in R software was used to build volcano maps, which are based on adjusted p-value and fold change. The results suggested that LSCC was associated with not only the aberrantly expressed mRNAs but also with the altered lncRNAs.

\section{Protein-protein interaction \& functional analyses of mRNAs}

The top 500 differentially expressed mRNAs were input into PPI for analyses via the String online tools (minimum required interaction score $=0.7$ ). To screen the hub protein in the PPI network, CentiScape was used to analyze the PPI network. A protein with connectivity of $>10$ as was defined as a hub protein based on the distribution density of nodes in the network. This resulted in 35 hub proteins which might play important roles in tumorigenesis of LSCC (Figure 1C). The most significant hub proteins were actinin alpha 2(ACTN2), myosin heavy chain 6(MYH6), titin-cap (TCAP), troponin i2 (TNNI2), Late Cornified Envelope Protein (LCE) , Small Proline-Rich Protein 2G (SPRR2G), Matrix Metallopeptidase 9 (MMP9) and Fibrinogen Alpha Chain (FGA). 
193

194

195

196

197

198

199

200

201

202

203

204

205

206

207

208

209

210

211

212

213

214

215

216

217

218

219

220

221

222

223

224

225

226

227

228

229

230

231

The potential regulatory roles of the identified mRNAs and how they affect LSCC pathogenesis were then studied. Both GO and KEGG enrichment analyses were used to determine the functions of aberrantly expressed mRNAs (see 'Materials \& methods'). GO enrichment analysis with DAVID indicated that differentially expressed mRNAs were mainly enriched in the following biological processes (BP) : extracellular matrix organization, collagen catabolic process, skeletal system development, epidermis development, adhesion and cell-cell signaling (Figure 1D). KEGG enrichment analysis via KOBAS showed that differentially expressed mRNAs were chiefly involved in the metabolic pathways, calcium signaling pathway, cytokine-cytokine receptor interaction, protein digestion and absorption, neuroactive ligand-receptor interaction and salivary secretion (Figure 1E). In addition, some common tumor-related pathways, such as cAMP, Jak, PI3K signaling pathway and pathways in cancer (Figure 1E) were also significantly enriched. Cytoscape plug-in was then applied for Go and KEGG enrichment analysis to further verify biological processes and signaling pathways. GO enrichment analysis with clueGO revealed that these mRNAs were involved in tissue development, multicellular organism development, muscle filament sliding, epithelium development, muscle system process, extracellular matrix organization, cell differentiation and extracellular structure organization (Figures 2A-K). Interestingly, the results of KEGG enrichment from clueGO were very similar to those of KOBAS. This results indicated that differentially expressed mRNAs were involved in cytokine-cytokine receptor interaction, maturity onset diabetes of the young, salivary secretion, calcium signaling pathway, protein digestion and absorption, neuroactive ligand-receptor interaction and ECM-receptor interaction (Figures 2L-O). Finally, the network of biological processes and signaling pathways was established base on co-expressed genes (Figure 2). This network suggested that these bioprocesses and signaling pathways might be related to the pathogenesis and development of LSCC.

\section{Expression and functional analysis of altered miRNAs in LSCC}

Differentially expressed lncRNAs and miRNAs were identified in laryngeal carcinoma. However, there was also a need to identify the expression of miRNAs for construction of ceRNA network. For this purpose, the miRNA expression quantification data of 117 LSCC samples and 12 normal samples were downloaded from TCGA. By comparing the LSCC group with the normal group, the significantly differentially expressed miRNAs were identified via the "edgeR" package in R software. By setting thresholds of $\mid \log 2$ foldchange (FC) $\mid>2.0$ and adjusted P-value $<0.01$, 55 aberrantly expressed miRNAs in LSCC were revealed. Of these, 33 miRNAs were upregulated and 22 miRNAs were downregulated. The top 30 of these miRNAs are presented in Table 4. Profiling and functional analyses was then performed. Similarly, a graphical overview of the miRNAs expression profile was generated using a volcano plot (Figure 3A). The volcano plot showed that the proportion of dysregulated miRNAs in laryngeal carcinoma is similar to lncRNAs or mRNAs. These results suggested that the lncRNA-miRNA-mRNA network might be an important regulatory mechanism in laryngeal cancer. 
232

233

234

235

236

237

238

239

240

241

242

243

244

245

246

247

248

249

250

251

252

253

254

255

256

257

258

259

260

261

262

263

264

265

266

267

268

269

270

To study the function of aberrantly expressed miRNAs, their target mRNAs were firstly predicted through miRTarBase and Miranda databases. clueGO was then used to conduct GO and KEGG enrichment analysis of these target mRNAs. Finally, miRNA-mRNA pairs were associated with biological processes and signaling pathways through CluePedia. The results revealed that EGFR, CTGF, COL4A2, FSTL1, CREB1, CDK4 and CDKN1A could be the key genes by which these miRNAs exerted regulatory function in LSCC (Figure 3B). GO enrichment analysis indicated that these target genes were enriched in bioprocesses, such as positive regulation of fibroblast proliferation, cellular response to amino acid stimulus, cellular response to fatty acid and response to amino acid(Figure 3B). Most importantly, KEGG analysis revealed that these target genes were involved in tumor-associated pathways, such as colorectal cancer, bladder cancer, non-small cell lung cancer, pancreatic cancer, melanoma and adherens junction (Figure 3B). These results suggests that the potential regulatory roles of aberrantly expressed miRNAs in LSCC might be one of the mechanisms of LSCC tumorigenesis.

\section{LncRNA-mediated ceRNA network revealed potential mechanisms of LSCC tumorigenesis}

To explore the regulatory mechanism between the lncRNA and mRNA transcripts, the lncRNA - miRNA - mRNA network was established based on the ceRNA hypothesis via their integrating expression profile data and their regulatory relationships. As described in 'Materials $\&$ methods' , the interaction between differentially expressed lncRNAs and miRNAs were firstly identified. The results revealed 114 lncRNA-miRNA pairs, consisting of 61 LncRNAs and 7 mRNAs ( Table 5). MiRTarBase, TargetScan and miRDB database were then used to predict miRNA-mRNA pairs. All the target mRNAs which matched with the databases were included in this study. A total of 90 target mRNAs (Table 6) were found. However, not all of these predicted target mRNAs were differentially expressed in LSCC. Therefore, the intersection of predicted mRNAs and all differentially expressed mRNAs was taken in the current study (Figure 3C). Finally, a co-expression network of RNAs was built by merging lncRNA-miRNA pairs and miRNA-mRNA pairs based on their shared miRNAs. As a result, 61 lncRNAs, 7 miRNAs and 7 target mRNAs were included in the ceRNA network (Table 5), and their regulatory relationships were visualized by Cytoscape(Figure 3D). This ceRNA network showed that complex interactions of IncRNA-miRNA-mRNA might be a potential cause of gene expression disorders in LSCC. GO and KEGG enrichment analysis showed that the target genes of ceRNA were mainly enriched in the following biological functions and pathways: biosynthetic process, regulation of macromolecule metabolic process, regulation of cellular metabolic process, hormone biosynthetic process, glycerophospholipid metabolism, thyroid hormone signaling pathway and transcriptional misregulation in cancer (Figures 4A and B). These results suggest that lncRNA-mediated ceRNA network might play an important role in tumorigenesis.

Survival analysis was performed to study the prognostic significance of ceRNA network. The expression profile data of RNAs in the ceRNA network and clinical information from TCGA was integrated to establish Kaplan-Meier curves. The results revealed that the aberrant 
271 expression of lncRNAs (TSPEAR-AS, CASK-AS1, MIR137HG, PART1, LSAMP-

272 AS1), miRNA (has-mir-210) and mRNAs (HOXC13, STC2, DIO1, FOXD4L1) had

273 significant effect on the prognosis of LSCC (Figures 4C-L). The results suggest that these key

274 RNAs in ceRNA networks could serve as prognostic biomarkers and their further studies might

275 contribute to LSCC therapy.

276

\section{Discussion}

278 Laryngeal squamous cell carcinoma, one of the most common tumors of the head and neck, has

279 been extensively studied to identify its key regulatory genes and molecules. This study

280 comprehensively analyzed the expression and function of aberrant RNAs and established a

281 ceRNA network of LSCC. 61 lncRNAs, 7 miRNAs and 7 target mRNAs were included in the 282 ceRNA network. Through analyzing the overall survival, 5 lncRNAs (TSPEAR-AS, CASK-

283 AS1, MIR137HG, PART1, LSAMP-AS1), miRNAs (has-mir-210), and 4 mRNAs

284

285

286

287

288

289

290

291

292

293

294

295

296

297

298

299

300

301

302

303

304

305

306

307

308

309

(HOXC13, STC2, DIO1, FOXD4L1) were found to be associated with overall survival in LSCC patients.

Using bioprocess and signaling pathway analyses, the biological functions and potential regulatory mechanisms of aberrantly expressed mRNAs were identified. GO and KEGG enrichment analyses associated these mRNAs with bioprocesses and pathways known to be involved in LSCC, including extracellular matrix organization, calcium signaling and metabolic pathways(Figures 1D, E, and Figures 2). PPI analysis of these altered mRNAs revealed that hub genes including MYH6, ACTN2, TCAP, TNNI2, LCE, SPRR2G, MMP9 and FGA might play crucial roles in LSCC tumorigenesis mechanisms (Figure 1C).

Recent evidence suggests that extracellular matrix (ECM) organization forms a tissuespecific microenvironment that plays a critical role in tumor progression and metastasis (InsuaRodriguez \& Oskarsson 2016; Walker et al. 2018; Zhou \& Lu 2017). The ECM is an extremely complex and dynamic molecular network surrounding tumor cells. As tumor cells proliferate, the surrounding ECM undergoes significant architectural changes through a dynamic interplay between the microenvironment and resident cells (Grossman et al. 2016). These changes are consistent with the findings (Figure 1D) in this work that bioprocess of extracellular matrix organization significantly enriched aberrant mRNAs of LSCC. Interestingly, a type IV collagenase matrix metalloprotease-9 (MMP9), which is identified as one of the most significant gene in PPI analysis, also plays an important role in ECM. MMP9 degrading collagen IV, which is a major component of basement membranes, facilitates tumor cells invasion(Malik et al. 2015). The increasing expression of MMP9 has been reported to be associated with metastasis, and poor prognosis in breast and colon cancer (Reggiani et al. 2017; Yang et al. 2017). Recent studies have shown that MMP9 increases tumor resistance to anti-PD-1(Zhao et al. 2018). This data indicates that normalization of ECM components and inhibition of MMP9 might be a promising strategy against LSCC. Indeed, previous experiment have predicted this possibility. For example, Sherman et al used agonist of stromal vitamin D receptor to reprogram

Peer) reviewing PDF | (2019:04:37198:1:1:NEW 13 Jun 2019) 
310 ECM by reducing fibrosis and increasing angiogenesis, and hence enhances the efficacy of

311

312

313

314

315

316

317

318

319

320

321

322

323

324

325

326

327

328

329

330

331

332

333

334

335

336

337

338

339

340

341

342

343

344

345

346

347

348

349 gemcitabine treatment in pancreatic cancer(Sherman et al. 2014). Isua-Rodriguez and Oskarsson summarized the target component of ECM in tumor therapy and highlighted the prospect of targeting ECM in breast cancer(Insua-Rodríguez \& Oskarsson 2016). Regarding LSCC, the results of the current study suggest that targeting ECM can start with inhibiting MMP9. It is worth noting that matrix metalloproteases (MMPs) are considered as promising targets against cancer in recent decades, but most clinical trials of MMP inhibitor have failed(Insua-Rodríguez \& Oskarsson 2016). This is caused by high toxicity and low selectivity(Coussens et al. 2002). Nevertheless, many new generation MMP inhibitor with higher selectivity are currently being developed and tested in cancer (Ager et al. 2015; Kaimal et al. 2013). Therefore, MMP inhibitors are still promising for the treatment of tumors.

Based on the results of pathway enrichment analysis, it was found that calcium signaling pathway might play an important role in LSCC tumorigenesis. As described in previous studies, calcium signaling is linked to key cell cycle, including early entry into G1 and progression through G1/S and G2/M (Prevarskaya et al. 2014; Roderick \& Cook 2008). Calcium signaling is also involved in specific oncogene and pro-oncogene pathways by which tumor cells generated resistance to apoptosis (Di et al. 2015; Lange et al. 2016; Tang et al. 2016). In addition, many studies focus on the effect of calcium signaling on tumor microenvironment, which guides tumor invasion and metastasis. For instance, activation of calcium-dependent kinase PNCK, results in macrophage recruitment, angiogenesis, and tumor progression by calcium-dependent NF- $\mathrm{KB}$ activation (Sang et al. 2018). Calcium signaling increasing HIF $1 \alpha$ stability contributes to the progression of hepatocarcinoma(Li et al. 2015). It is as if environmental factor, hypoxia, can be transmitted to tumor cells via calcium signaling. Moreover, calcium signaling has been found to directly regulate cancer cells death induced by cytotoxic T lymphocytes and NK cells(Monteith et al. 2017). Targeting calcium signaling is a promising strategy for cancer therapy. Inhibitors of TRPV6, the highly Ca2+ selective ion channel, has now undergone phase I clinical trials in patients with advanced tumors(Fu et al. 2017). Targeting calcium signaling can reactivate tumor suppressor genes silenced by calciumcalmodulin kinase and increase cell death in colon cancer (Raynal et al. 2016). Moreover, suppression of $\mathrm{Ca} 2+$ channels has be showed to inhibit the proliferation of LSCC cell line in vitro(Yu et al. 2014). However, to date there are very few studies on calcium signaling in LSCC. In brief, the current results highlighted the importance of ECM and calcium pathways for their potential therapeutic value in LSCC.

LncRNAs, composed of $>200$ nucleotides (nt) without protein-coding ability, play an important role in epigenetic, transcriptional, post-transcriptional and translational regulation (Khorkova et al. 2015). Previous profiling studies suggest that the aberrant expression of lncRNA in LSCC may be a potential mechanism of tumorigenesis and development, and might become biomarkers for diagnosis and prognosis (Gong et al. 2014; Parasramka et al. 2016; Rupaimoole et al. 2015; Yuan et al. 2014). As described in Salmena's ceRNA hypothesis, lncRNAs competitively bind to miRNAs via their intramolecular miRNA reaction elements 
350

351

352

353

354

355

356

357

358

359

360

361

362

363

364

365

366

367

368

369

370

371

372

373

374

375

376

377

378

379

380

381

382

383

384

385

386

387

388

389

(MREs) to participate in post-transcriptional regulation(Salmena et al. 2011). Numerous studies have suggested that ceRNA networks play an important role in the regulation of gene expression in cancers, such as gastric cancer, breast cancer, endometrial cancer, thyroid cancer, and lymphoma (Guo et al. 2015; Wang et al. 2016c). In this study, the lncRNA-mediated ceRNA regulatory network was analyzed to explore potential novel regulatory mechanisms for lncRNAs in LSCC. Moreover, 5 lncRNAs（TSPEAR-AS, CASK-AS1, MIR137HG, PART1, LSAMP-AS1) that correlated with the prognosis of patients with LSCC were screened.

As described in previous studies, high lncRNA PART1 expression is associated with poor prognosis and tumor recurrence in non-small cell lung cancer (Li et al. 2017a). Elevated PART1 is found in esophageal squamous cell carcinoma and promotes gefitinib resistance by competitively binding to miR-129 to facilitate Bcl-2 expression (Kang et al. 2018). Moreover, PART1 upregulated by androgen is reported to promote cell proliferation and inhibit apoptosis via Toll-like receptor pathway in prostate cancer(Sun et al. 2018). Interestingly, the larynx is also considered a secondary sexual organ and the androgen receptor is highly upregulated in LSCC(Fei et al. 2018). These data indicates that PART1 also play an important role in LSCC. The current results showed that PART1 was negatively correlated to survival rate in LSCC and could be a prognosis biomarker. These results are consistent with findings in other HNSCC, including oral squamous cell carcinoma and tongue squamous cell carcinoma (Li et al. 2017b; Zhang et al. 2019).

LSAMP-AS1, also called LOC285194 or Tumor Suppressor Candidate 7(TUSC7), was previously defined as a tumor suppressor in esophageal squamous cell carcinoma (ESCC) and colorectal cancer (Liu et al. 2013; Qi et al. 2013; Tong et al. 2014). LSAMP-AS1/miR-224 regulates proliferation, apoptosis, and chemotherapy resistance of ESCC by regulating DESC1/EGFR/AKT pathway(Chang et al. 2018). LSAMP-AS1 inhibits proliferation by sponging miR-211 in colorectal cancer(Xu et al. 2017). Nevertheless, the current study suggested that LSAMP-AS1 might be an up-regulation promotor in LSCC with poor prognosis. A reasonable explanation for this discrepancy might be that LSAMP-AS1 influences the LSCC pathogenesis through other mechanisms. In this work, upregulated LSAMP-AS1 directly inhibited miR-375 in the ceRNA network. MiR-375 is downregulated and considered as a tumor suppressor in LSCC (Guo et al. 2016; Wang et al. 2016a). MiR-375 targets IGF1R and affects its downstream AKT signaling pathways which contributes to inhibition of cell progression in LSCC(Luo et al. 2014). The results in the current work indicate that downregulation of miR-375 has effects on upregulated LSAMP-AS1. While LSAMP-AS1 may play an important role in LSCC by targeting miR-375. However, these results should be further confirmed in vivo and in vitro.

The current study identified has-miR-210 related to the diagnosis and prognosis of LSCC. Several existing studies indicate that has-mir-210 may serve as a marker for tumor hypoxia and a prognostic factor in HNSCC (Gee et al. 2010; Huang et al. 2009). Has-miR-210 is robustly and consistently induced in response to hypoxia. Recent studies showed that has-mir210 is up-regulated in HNSCC sample and inhibits proliferation of tumor cells (Zuo et al. 2015).

Peer) reviewing PDF | (2019:04:37198:1:1:NEW 13 Jun 2019) 
390 These data are consistent with the current findings that hsa-miR-210 is up-regulated and

391

392

393

394

395

396

397

398

399

400

401

402

403

404

405

406

407

408

409

410

411

412

413

414

415

416

417

418

419

420

421

422

423

424

425

426

427

428

429

positively correlated with prognosis. It has been clearly established that Hypoxia-inducible factor-1 (HIF1), as one of the genes that is induced by hypoxia, directly increases the expression of has-mir-210(Gee et al. 2010; Huang et al. 2009; Merlo et al. 2012). However, the differential expression of HIF1 between LSCC and normal samples was not found in the current study. This result suggests that other mechanisms are involved in the regulation of has-miR-210 expression in LSCC. In the current ceRNA network, low expression of lncRNA ALDH1L1-AS2 and EMX2OS was involved in up-regulation of has-mir-210. Although the function of these two IncRNA has not been studied, the results indicated that the two lncRNAs regulates the expression of GPD1L by competitively inhibiting has-miR-210. Similarly, hypoxia induced GPD1L can decrease the subunit of HIF1 protein. HIF1 protein mediates hypoxic responses and regulates gene expression involved in angiogenesis, invasion and metabolism(Kim et al. 2016). Previous reports showed that GPD1L as a direct target of has-mir-210 is positively associated with prognosis in HNSCC (Feng et al. 2014; Kelly et al. 2011b). The down-regulation of GPD1L by miR-210 occurs in vivo and contributes to HIF1 stability, which enhance the metastatic and invasiveness of cancer (Costales et al. 2017; Gee et al. 2014; Kelly et al. 2011a). Therefore, ALDH1L1-AS2 or EMX2OS targeting has-miR-210/GPD1L may regulate LSCC development by HIF1.

In this study, we used bioinformatics to analyze the expression and function of aberrantly expressed lncRNA, miRNA, and mRNA in LSCC and establish a ceRNA network to predict the regulation mechanism of lncRNA. In a previous report, Feng et al used a similar method to establish ceRNA network in LSCC(Feng et al. 2016). Feng et al analyzed differentially expressed lncRNA and mRNA via Microarray assay. Some results of Feng's study are similar to ours, that the extracellular matrix, metabolic pathway, and hypoxia-induced HIF 1 are important in LSCC(Feng et al. 2016). However, Feng et al did not perform a differential analysis of miRNAs. This may lead to the fact that the miRNAs in their ceRNA networks are not abnormally expressed in LSCC. In addition, Feng et al did not analyze the prognostic significance of the screened RNA. In our study, expression data we used comes from highthroughput sequencing and contain a larger sample size. The aberrantly expressed lncRNAs, miRNAs, and mRNAs in LSCC were utilized to construct the ceRNA network and the survival analysis of them identified their prognostic significance.However, some limitations of the current study should be acknowledged. The function of lncRNA is complex. This study only analyzed one mechanism of lncRNA competitively combining miRNA. Moreover, the database, used to predict interactions between these RNAs, is outdated. This may had caused the omission of some important information. Contradictory results may occur between different bioinformatics analyses because of different platforms, different parameter settings and different correction methods. Therefore, further experimental or clinical studies are needed to validate these results.

\section{Conclusions}

Peer) reviewing PDF | (2019:04:37198:1:1:NEW 13 Jun 2019) 
430 The current study identified differentially expressed lncRNA, miRNA and mRNA via RNA-

431 Seq data of large-scale samples from TCGA. GO and KEGG enrichment analysis identified the 432 regulatory roles of altered RNAs but the precise regulatory mechanisms need further study. The 433 construction of the ceRNA network broadens the understanding of mechanisms by which 434 lncRNAs are involved in tumorigenesis. In this network, 5 lncRNAs (TSPEAR-AS, CASK435 AS1, MIR137HG, PART1, LSAMP-AS1), miRNA (has-mir-210), and 4 mRNAs (HOXC13, STC2, DIO1, FOXD4L1) were found to be associated with overall survival of LSCC patients. It is noteworthy that the results in this study were predicted via bioinformatics and therefore should be verified through in vivo and in vitro experiments.

439

440

441

442

443

444

445

446

447

448

449

450

451

452

453

454

455

456

457

458

459

460

461

462

463

464

465

466

467

468

469

470

\section{Acknowledgements}

This studies were supported by Natural Science Foundation of China (81760184).

\section{References}

Ager EI, Kozin SV, Kirkpatrick ND, Seano G, Kodack DP, Askoxylakis V, Huang Y, Goel S, Snuderl M, Muzikansky A, Finkelstein DM, Dransfield DT, Devy L, Boucher Y, Fukumura D, and Jain RK. 2015. Blockade of MMP14 activity in murine breast carcinomas: implications for macrophages, vessels, and radiotherapy. J Natl Cancer Inst 107.

Berindan-Neagoe I, Monroig PC, Pasculli B, and Calin GA. 2014. MicroRNAome genome: a treasure for cancer diagnosis and therapy. CA Cancer J Clin 64:311-336.

Bindea G, Mlecnik B, Hackl H, Charoentong P, Tosolini M, Kirilovsky A, Fridman WH, Pages F, Trajanoski Z, and Galon J. 2009. ClueGO: a Cytoscape plug-in to decipher functionally grouped gene ontology and pathway annotation networks. Bioinformatics 25:1091-1093.

Chang ZW, Jia YX, Zhang WJ, Song LJ, Gao M, Li MJ, Zhao RH, Li J, Zhong YL, Sun QZ, and Qin YR. 2018. LncRNA-TUSC7/miR-224 affected chemotherapy resistance of esophageal squamous cell carcinoma by competitively regulating DESC1. J Exp Clin Cancer Res 37:56.

Costales MG, Haga CL, Velagapudi SP, Childs-Disney JL, Phinney DG, and Disney MD. 2017. Small Molecule Inhibition of microRNA-210 Reprograms an Oncogenic Hypoxic Circuit. 139:3446-3455.

Coussens LM, Fingleton B, and Matrisian LM. 2002. Matrix metalloproteinase inhibitors and cancer: trials and tribulations. Science 295:2387-2392.

Di Leva G, Garofalo M, and Croce CM. 2014. MicroRNAs in cancer. Annu Rev Pathol 9:287314.

Fei M, Zhang J, Zhou J, Xu Y, and Wang J. 2018. Sex-related hormone receptor in laryngeal squamous cell carcinoma: correlation with androgen estrogen-a and prolactin receptor expression and influence of prognosis. Acta Otolaryngol 138:66-72. 
471 Feng L, Wang R, Lian M, Ma H, He N, Liu H, Wang H, and Fang J. 2016. Integrated Analysis

472

473

474

475

476

477

478

479

480

481

482

483

484

485

486

487

488

489

490

491

492

493

494

495

496

497

498

499

500

501

502

503

504

505

506

507

508

509

510

511

512

513

514

515

516 of Long Noncoding RNA and mRNA Expression Profile in Advanced Laryngeal Squamous Cell Carcinoma. PLoS One 11:e0169232.

Feng Z, Li JN, Wang L, Pu YF, Wang Y, and Guo CB. 2014. The prognostic value of glycerol3-phosphate dehydrogenase 1-like expression in head and neck squamous cell carcinoma. Histopathology 64:348-355.

Friedman RC, Farh KK, Burge CB, and Bartel DP. 2009. Most mammalian mRNAs are conserved targets of microRNAs. Genome Res 19:92-105.

Fu S, Hirte H, Welch S, Ilenchuk TT, Lutes T, Rice C, Fields N, Nemet A, Dugourd D, PihaPaul S, Subbiah V, Liu L, Gong J, Hong D, and Stewart JM. 2017. First-in-human phase I study of SOR-C13, a TRPV6 calcium channel inhibitor, in patients with advanced solid tumors. Invest New Drugs 35:324-333.

Gee HE, Camps C, Buffa FM, Patiar S, Winter SC, Betts G, Homer J, Corbridge R, Cox G, West CM, Ragoussis J, and Harris AL. 2010. hsa-mir-210 is a marker of tumor hypoxia and a prognostic factor in head and neck cancer. Cancer 116:2148-2158.

Gee HE, Ivan C, Calin GA, and Ivan M. 2014. HypoxamiRs and cancer: from biology to targeted therapy. Antioxid Redox Signal 21:1220-1238.

Gong Z, Zhang S, Zeng Z, Wu H, Yang Q, Xiong F, Shi L, Yang J, Zhang W, Zhou Y, Zeng Y, Li X, Xiang B, Peng S, Zhou M, Li X, Tan M, Li Y, Xiong W, and Li G. 2014. LOC401317, a p53-Regulated Long Non-Coding RNA, Inhibits Cell Proliferation and Induces Apoptosis in the Nasopharyngeal Carcinoma Cell Line HNE2. PLoS ONE 9:e110674.

Groome PA, O Sullivan B, Irish JC, Rothwell DM, Schulze K, Warde PR, Schneider KM, Mackenzie RG, Hodson DI, Hammond JA, Gulavita SPP, Eapen LJ, Dixon PF, Bissett RJ, and Mackillop WJ. 2003. Management and Outcome Differences in Supraglottic Cancer Between Ontario, Canada, and the Surveillance, Epidemiology, and End Results Areas of the United States. Journal of Clinical Oncology 21:496-505.

Grossman M, Ben-Chetrit N, Zhuravlev A, Afik R, Bassat E, Solomonov I, Yarden Y, and Sagi I. 2016. Tumor Cell Invasion Can Be Blocked by Modulators of Collagen Fibril Alignment That Control Assembly of the Extracellular Matrix. Cancer Res 76:42494258.

Guo LL, Song CH, Wang P, Dai LP, Zhang JY, and Wang KJ. 2015. Competing endogenous RNA networks and gastric cancer. World J Gastroenterol 21:11680-11687.

Guo Y, An R, Zhao R, Sun Y, Liu M, and Tian L. 2016. miR-375 exhibits a more effective tumor-suppressor function in laryngeal squamous carcinoma cells by regulating KLF4 expression compared with simple co-transfection of miR-375 and miR-206. Oncol Rep 36:952-960.

Huang C, Yuan N, Wu L, Wang X, Dai J, Song P, Li F, Xu C, and Zhao X. 2017. An integrated analysis for long noncoding RNAs and microRNAs with the mediated competing endogenous RNA network in papillary renal cell carcinoma. Onco Targets Ther 10:40374050.

Huang X, Ding L, Bennewith KL, Tong RT, Welford SM, Ang KK, Story M, Le QT, and Giaccia AJ. 2009. Hypoxia-inducible mir-210 regulates normoxic gene expression involved in tumor initiation. Mol Cell 35:856-867.

Insua-Rodríguez J, and Oskarsson T. 2016. The extracellular matrix in breast cancer. Adv Drug Deliv Rev 97:41-55. 
517 Insua-Rodriguez J, and Oskarsson T. 2016. The extracellular matrix in breast cancer. Adv Drug 518 Deliv Rev 97:41-55.

519

520

521

522

523

524

525

526

527

528

529

530

531

532

533

534

535

536

537

538

539

540

541

542

543

544

545

546

547

548

549

550

551

552

553

554

555

556

557

558

559

560

561

562

Kaimal R, Aljumaily R, Tressel SL, Pradhan RV, Covic L, Kuliopulos A, Zarwan C, Kim YB, Sharifi S, and Agarwal A. 2013. Selective blockade of matrix metalloprotease-14 with a monoclonal antibody abrogates invasion, angiogenesis, and tumor growth in ovarian cancer. Cancer Res 73:2457-2467.

Kang M, Ren M, Li Y, Fu Y, Deng M, and Li C. 2018. Exosome-mediated transfer of lncRNA PART1 induces gefitinib resistance in esophageal squamous cell carcinoma via functioning as a competing endogenous RNA. J Exp Clin Cancer Res 37:171.

Kelly TJ, Souza AL, Clish CB, and Puigserver P. 2011a. A hypoxia-induced positive feedback loop promotes hypoxia-inducible factor 1alpha stability through miR-210 suppression of glycerol-3-phosphate dehydrogenase 1-like. J Am Chem Soc 31:2696-2706.

Kelly TJ, Souza AL, Clish CB, and Puigserver P. 2011b. A hypoxia-induced positive feedback loop promotes hypoxia-inducible factor 1alpha stability through miR-210 suppression of glycerol-3-phosphate dehydrogenase 1-like. Mol Cell Biol 31:2696-2706.

Khorkova O, Hsiao J, and Wahlestedt C. 2015. Basic biology and therapeutic implications of lncRNA. Adv Drug Deliv Rev 87:15-24.

Kim Y, Nam HJ, Lee J, Park DY, Kim C, Yu YS, Kim D, Park SW, Bhin J, Hwang D, Lee H, Koh GY, and Baek SH. 2016. Methylation-dependent regulation of HIF-1 $\alpha$ stability restricts retinal and tumour angiogenesis. Nat Commun 7:10347.

Li M, Zhang W, Zhang S, Wang C, and Lin Y. 2017a. PART1 expression is associated with poor prognosis and tumor recurrence in stage I-III non-small cell lung cancer. J Cancer 8:1795-1800.

Li S, Chen X, Liu X, Yu Y, Pan H, Haak R, Schmidt J, Ziebolz D, and Schmalz G. 2017b. Complex integrated analysis of lncRNAs-miRNAs-mRNAs in oral squamous cell carcinoma. Oral Oncol 73:1-9.

Li Y, Guo B, Xie Q, Ye D, Zhang D, Zhu Y, Chen H, and Zhu B. 2015. STIM1 Mediates Hypoxia-Driven Hepatocarcinogenesis via Interaction with HIF-1. Cell Rep 12:388-395.

Liu Q, Huang J, Zhou N, Zhang Z, Zhang A, Lu Z, Wu F, and Mo YY. 2013. LncRNA loc285194 is a p53-regulated tumor suppressor. Nucleic Acids Res 41:4976-4987.

Luo J, Wu J, Li Z, Qin H, Wang B, Wong TS, Yang W, Fu QL, and Lei W. 2014. miR-375 suppresses IGF1R expression and contributes to inhibition of cell progression in laryngeal squamous cell carcinoma. Biomed Res Int 2014:374598.

Malik R, Lelkes PI, and Cukierman E. 2015. Biomechanical and biochemical remodeling of stromal extracellular matrix in cancer. Trends Biotechnol 33:230-236.

McGuire A, Brown JA, and Kerin MJ. 2015. Metastatic breast cancer: the potential of miRNA for diagnosis and treatment monitoring. Cancer Metastasis Rev 34:145-155.

Merlo A, de Quiros SB, Secades P, Zambrano I, Balbin M, Astudillo A, Scola B, Aristegui M, Suarez C, and Chiara MD. 2012. Identification of a signaling axis HIF1alpha/microRNA-210/ISCU independent of SDH mutation that defines a subgroup of head and neck paragangliomas. J Clin Endocrinol Metab 97:E2194-2200.

Monteith GR, Prevarskaya N, and Roberts-Thomson SJ. 2017. The calcium-cancer signalling nexus. Nat Rev Cancer 17:367-380.

Parasramka MA, Maji S, Matsuda A, Yan IK, and Patel T. 2016. Long non-coding RNAs as novel targets for therapy in hepatocellular carcinoma. Pharmacology \& Therapeutics 161:67-78.

Peer) reviewing PDF | (2019:04:37198:1:1:NEW 13 Jun 2019) 
563 Qi P, Xu MD, Ni SJ, Huang D, Wei P, Tan C, Zhou XY, and Du X. 2013. Low expression of

564

565

566

567

568

569

570

571

572

573

574

575

576

577

578

579

580

581

582

583

584

585

586

587

588

589

590

591

592

593

594

595

596

597

598

599

600

601

602

603

604

605

606

607

608 LOC285194 is associated with poor prognosis in colorectal cancer. J Transl Med 11:122.

Raynal NJ, Lee JT, Wang Y, Beaudry A, Madireddi P, Garriga J, Malouf GG, Dumont S, Dettman EJ, Gharibyan V, Ahmed S, Chung W, Childers WE, Abou-Gharbia M, Henry RA, Andrews AJ, Jelinek J, Cui Y, Baylin SB, Gill DL, and Issa JP. 2016. Targeting Calcium Signaling Induces Epigenetic Reactivation of Tumor Suppressor Genes in Cancer. Cancer Res 76:1494-1505.

Rupaimoole R, Lee J, Haemmerle M, Ling H, Previs RA, Pradeep S, Wu SY, Ivan C, Ferracin M, Dennison JB, Millward NMZ, Nagaraja AS, Gharpure KM, McGuire M, Sam N, Armaiz-Pena GN, Sadaoui NC, Rodriguez-Aguayo C, Calin GA, Drapkin RI, Kovacs J, Mills GB, Zhang W, Lopez-Berestein G, Bhattacharya PK, and Sood AK. 2015. Long Noncoding RNA Ceruloplasmin Promotes Cancer Growth by Altering Glycolysis. Cell Reports 13:2395-2402.

Salmena L, Poliseno L, Tay Y, Kats L, and Pandolfi PP. 2011. A ceRNA hypothesis: the Rosetta Stone of a hidden RNA language? Cell 146:353-358.

Sang LJ, Ju HQ, Liu GP, Tian T, Ma GL, Lu YX, Liu ZX, Pan RL, Li RH, Piao HL, Marks JR, Yang LJ, Yan Q, Wang W, Shao J, Zhou Y, Zhou T, and Lin A. 2018. LncRNA CamK-A Regulates Ca-Signaling-Mediated Tumor Microenvironment Remodeling. Mol Cell 72:71-83.e77.

Sherman MH, Yu RT, Engle DD, Ding N, Atkins AR, Tiriac H, Collisson EA, Connor F, Van Dyke T, Kozlov S, Martin P, Tseng TW, Dawson DW, Donahue TR, Masamune A, Shimosegawa T, Apte MV, Wilson JS, Ng B, Lau SL, Gunton JE, Wahl GM, Hunter T, Drebin JA, O'Dwyer PJ, Liddle C, Tuveson DA, Downes M, and Evans RM. 2014. Vitamin D receptor-mediated stromal reprogramming suppresses pancreatitis and enhances pancreatic cancer therapy. Cell 159:80-93.

Shin VY, and Chu KM. 2014. MiRNA as potential biomarkers and therapeutic targets for gastric cancer. World J Gastroenterol 20:10432-10439.

Siegel RL, Miller KD, and Jemal A. 2018. Cancer statistics, 2018. CA Cancer J Clin 68:7-30.

Steuer CE, El-Deiry M, Parks JR, Higgins KA, and Saba NF. 2017. An update on larynx cancer. CA Cancer J Clin 67:31-50.

Sun M, Geng D, Li S, Chen Z, and Zhao W. 2018. LncRNA PART1 modulates toll-like receptor pathways to influence cell proliferation and apoptosis in prostate cancer cells. Biol Chem 399:387-395.

Tong YS, Zhou XL, Wang XW, Wu QQ, Yang TX, Lv J, Yang JS, Zhu B, and Cao XF. 2014. Association of decreased expression of long non-coding RNA LOC285194 with chemoradiotherapy resistance and poor prognosis in esophageal squamous cell carcinoma. J Transl Med 12:233.

Walker C, Mojares E, and Del R"a o Hern" $\notin$ ndez A. 2018. Role of Extracellular Matrix in Development and Cancer Progression. International Journal of Molecular Sciences 19:3028.

Wan G, Zhou L, Xie M, Chen H, and Tian J. 2010. Characterization of side population cells from laryngeal cancer cell lines. Head Neck 32:1302-1309.

Wang B, Lv K, Chen W, Zhao J, Luo J, Wu J, Li Z, Qin H, Wong TS, Yang W, Fu QL, and Lei W. 2016a. miR-375 and miR-205 Regulate the Invasion and Migration of Laryngeal Squamous Cell Carcinoma Synergistically via AKT-Mediated EMT. Biomed Res Int 2016:9652789. 
609 Wang P, Wu T, Zhou H, Jin Q, He G, Yu H, Xuan L, Wang X, Tian L, Sun Y, Liu M, and Qu L.

610

611

612

613

614

615

616

617

618

619

620

621

622

623

624

625

626

627

628

629

630

631

632

633

634

635

636

637

638

639

640

641

642

643 2016b. Long noncoding RNA NEAT1 promotes laryngeal squamous cell cancer through regulating miR-107/CDK6 pathway. J Exp Clin Cancer Res 35:22.

Wang Y, Hou J, He D, Sun M, Zhang P, Yu Y, and Chen Y. 2016c. The Emerging Function and Mechanism of ceRNAs in Cancer. Trends Genet 32:211-224.

$\mathrm{Xu}$ J, Zhang R, and Zhao J. 2017. The Novel Long Noncoding RNA TUSC7 Inhibits Proliferation by Sponging MiR-211 in Colorectal Cancer. Cell Physiol Biochem 41:635644.

Yu W, Wang P, Ma H, Zhang G, Yulin Z, Lu B, Wang H, and Dong M. 2014. Suppression of Ttype $\mathrm{Ca} 2+$ channels inhibited human laryngeal squamous cell carcinoma cell proliferation running title: roles of T-type Ca2+ channels in LSCC cell proliferation. Clin Lab 60:621628.

Yuan J-h, Yang F, Wang F, Ma J-z, Guo Y-j, Tao Q-f, Liu F, Pan W, Wang T-t, Zhou C-c, Wang S-b, Wang Y-z, Yang Y, Yang N, Zhou W-p, Yang G-s, and Sun S-h. 2014. A Long Noncoding RNA Activated by TGF-| $\hat{A}$ Promotes the Invasion-Metastasis Cascade in Hepatocellular Carcinoma. Cancer Cell 25:666-681.

Yuan Z, Xiu C, Song K, Pei R, Miao S, Mao X, Sun J, and Jia S. 2018. Long non-coding RNA AFAP1-AS1/miR-320a/RBPJ axis regulates laryngeal carcinoma cell stemness and chemoresistance. J Cell Mol Med 22:4253-4262.

Zhang S, Cao R, Li Q, Yao M, Chen Y, and Zhou H. 2019. Comprehensive analysis of lncRNAassociated competing endogenous RNA network in tongue squamous cell carcinoma. PeerJ 7:e6397.

Zhao F, Evans K, Xiao C, DeVito N, Theivanthiran B, Holtzhausen A, Siska PJ, Blobe GC, and Hanks BA. 2018. Stromal Fibroblasts Mediate Anti-PD-1 Resistance via MMP-9 and Dictate TGF $\beta$ Inhibitor Sequencing in Melanoma. Cancer Immunol Res 6:1459-1471.

Zhao J, Lv K, Li ZH, Wu J, Gao W, Wong TS, Luo J, Qin H, Wang B, Fu Q, and Lei WB. 2017. Functional significance of the long non-coding RNA RP11-169D4.1 as a metastasis suppressor in laryngeal squamous cell carcinoma by regulating CDH1. Oncol Rep 38:211-220.

Zhou Z, and Lu ZR. 2017. Molecular imaging of the tumor microenvironment. Adv Drug Deliv Rev 113:24-48.

Zuo J, Wen M, Lei M, Peng X, Yang X, and Liu Z. 2015. MiR-210 links hypoxia with cell proliferation regulation in human Laryngocarcinoma cancer. J Cell Biochem 116:10391049. 


\section{Figure 1}

Figure 1. Volcano plots, protein-protein interaction $\square G O$ (BP) and KEGG enrichment analyses for differentially expressed mRNAs and long noncoding RNAs

Volcano plots are used to visualize and assess the variation of (A) IncRNAs, (B) mRNAs expression between LSCC tissues and normal tissues. (C) The PPI networks of altered mRNAs. Each rectangle corresponds to a protein-coding gene (mRNA). Colors represent different connectivity (blue $<10$, yellow $\geq 10$ orange $\geq 15$ and purple $\geq 20$ ). Top 30 (D) biological processes and (E) pathways of significantly differentially expressed mRNAs in the GO analysis and KEGG analysis, respectively. The horizontal axis represents the number of enriched genes and the intensity of color represents corrected P-value. 

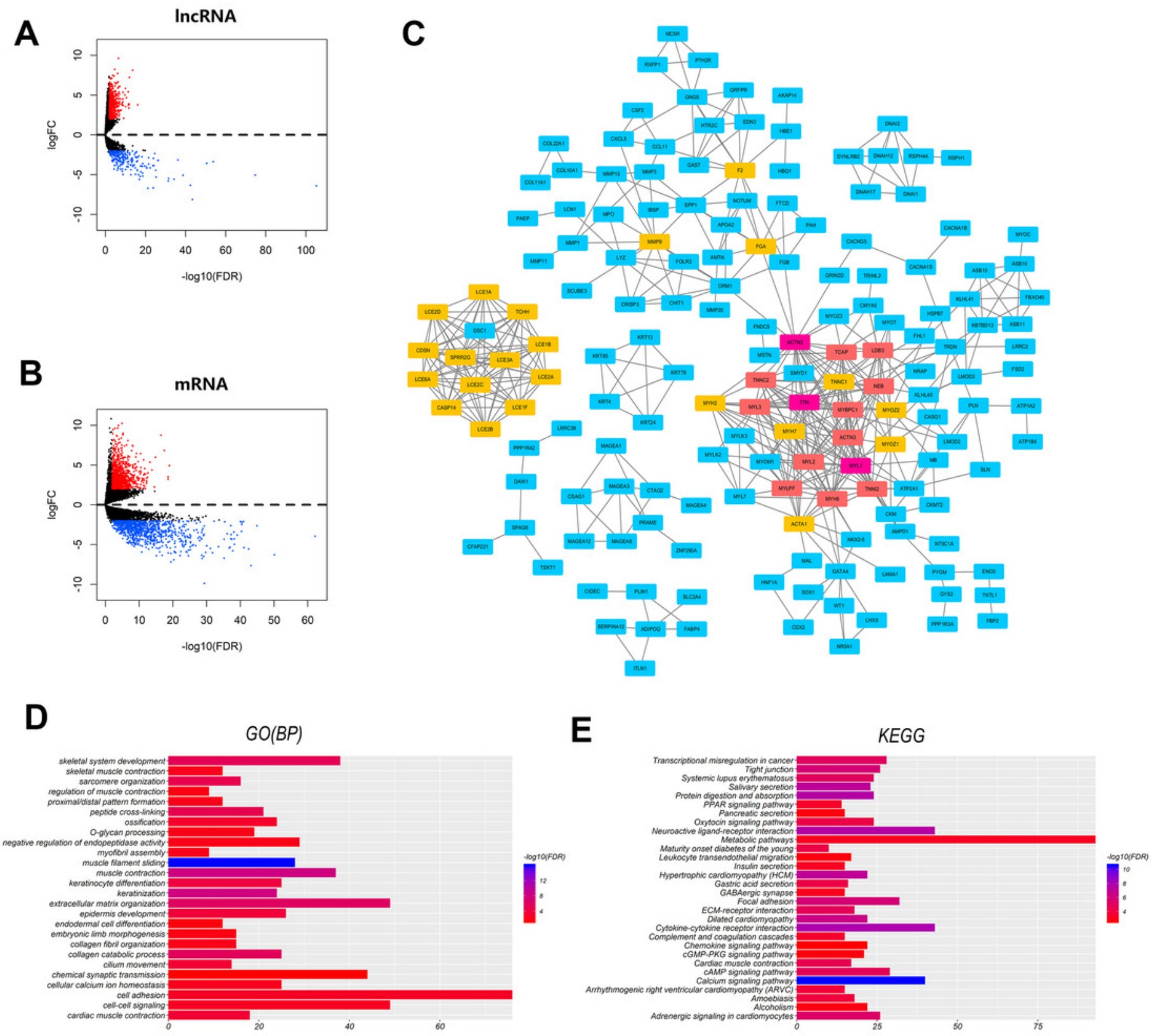
Figure 2

Figure 2. Network view of processes and pathways of aberrantly expressed mRNAs using ClueGO and CluePedia

Functionally grouped network with (A-K) processes and (L-O) pathways as nodes linked based on their co-expressed genes ( $\mathrm{k}$-score $\geq 0.4$ ). The most significant processes and pathways in each group are marked. The node size represents enrichment level. 


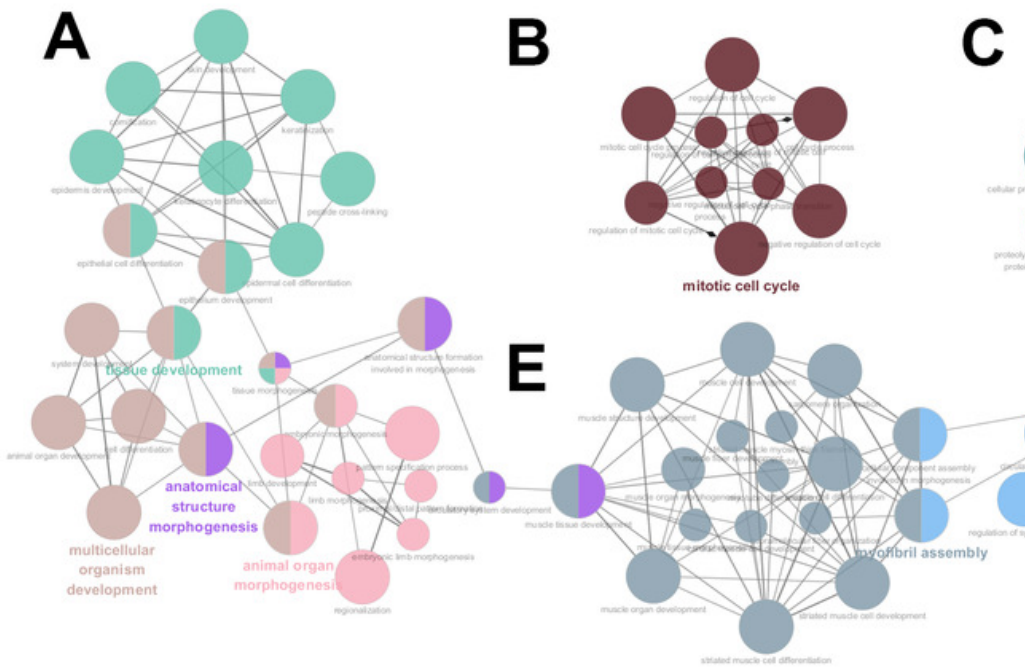

G

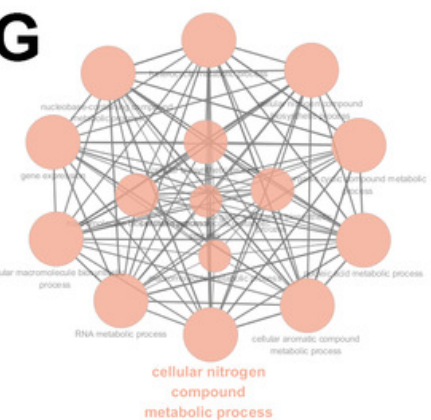

H

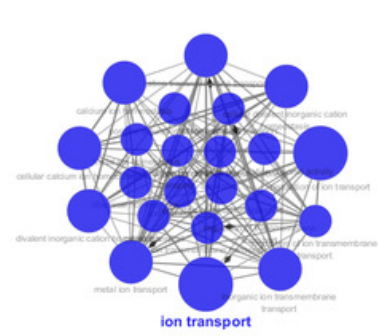

K
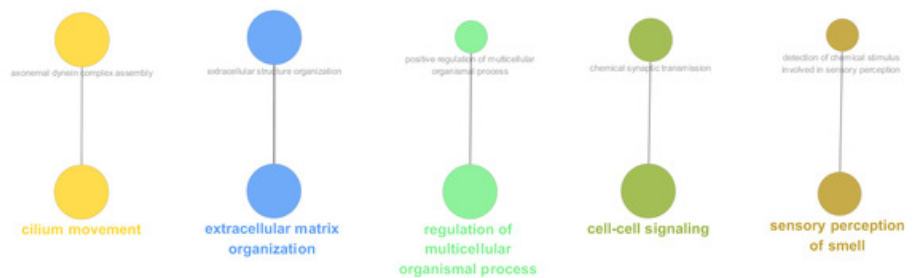

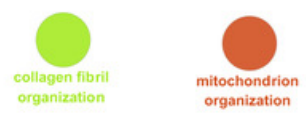
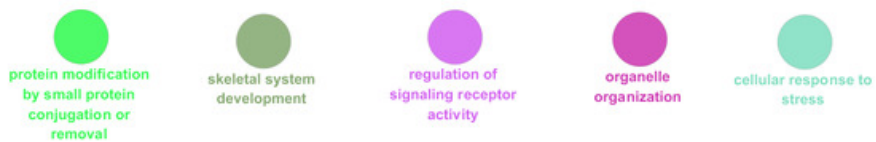

$\overbrace{\substack{\text { organic acid } \\ \text { biosynthetic } \\ \text { process }}}$ O-glycan processing

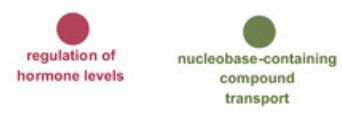

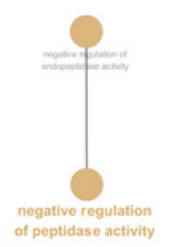
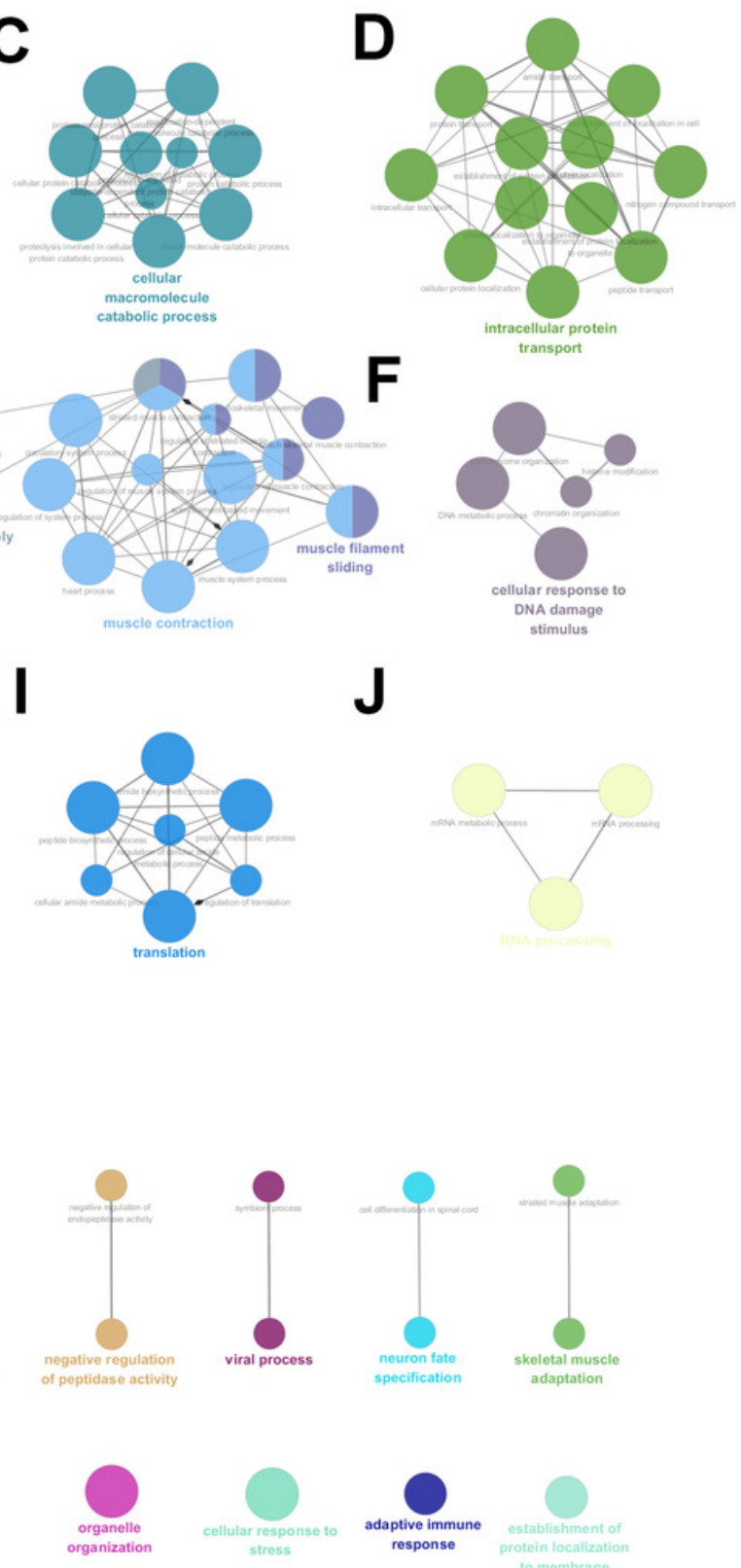

F

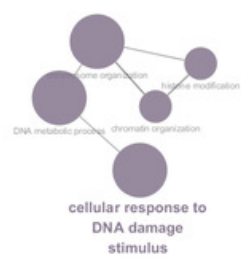

J
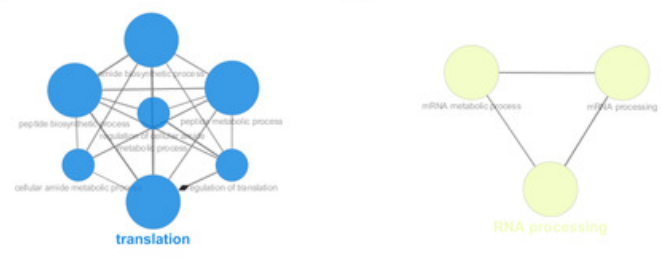

response
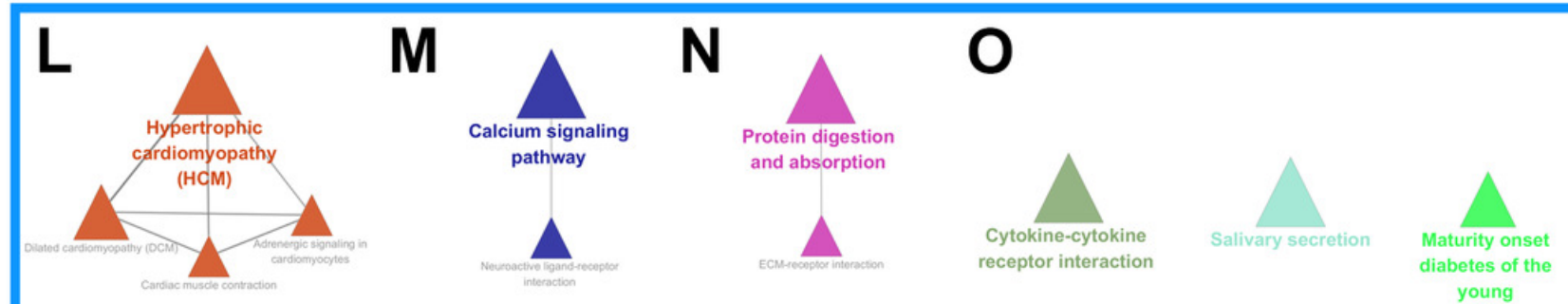


\section{Figure 3}

Figure 3. Functional analysis of differentially expressed miRNA and ceRNA network in LSCC

(A) Vocalno plot indicating the significantly differentially expressed miRNAs in LSCC ( $p<0.01$ and fold change of $>2$ ). (B) GO and KEGG enrichment analysis of the target genes of altered miRNAs. The association between miRNA-mRNA pairs, biological processes, and signaling pathways was determined by CluePedia. Pink squares represent differentially expressed miRNAs, and yellow circles represent target genes. Blue circles and triangles represent processes and pathways, respectively. (C) Venn diagram showing the intersection of the predicted mRNAs and all differentially expressed mRNAs. (D) The global view of the ceRNA network in LSCC. Diamonds and squares represent IncRNAs and miRNAs, respectively. Ovals represent mRNAs. Red nodes represent upregulation and blue nodes represent downregulation. 
A

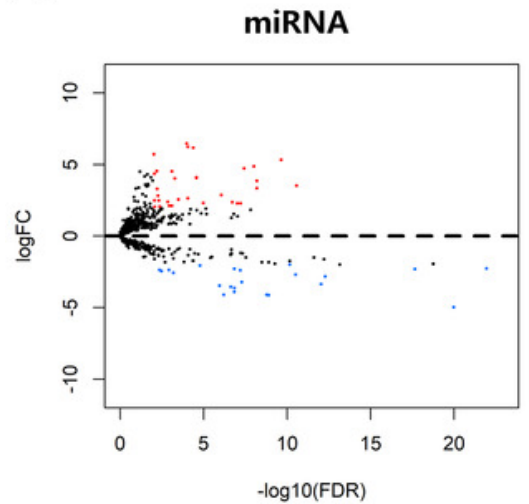

C

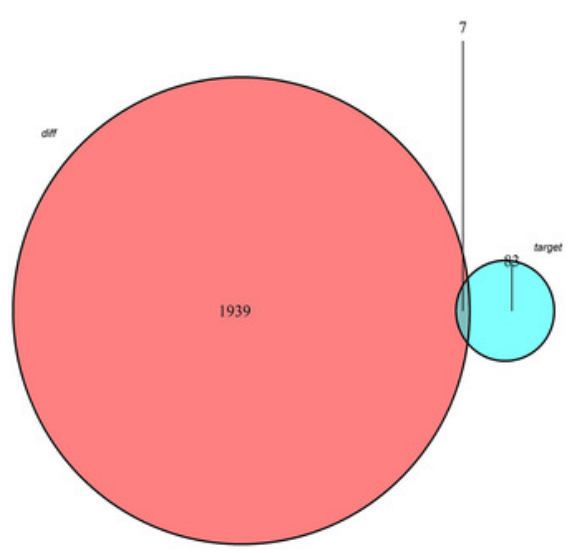

B

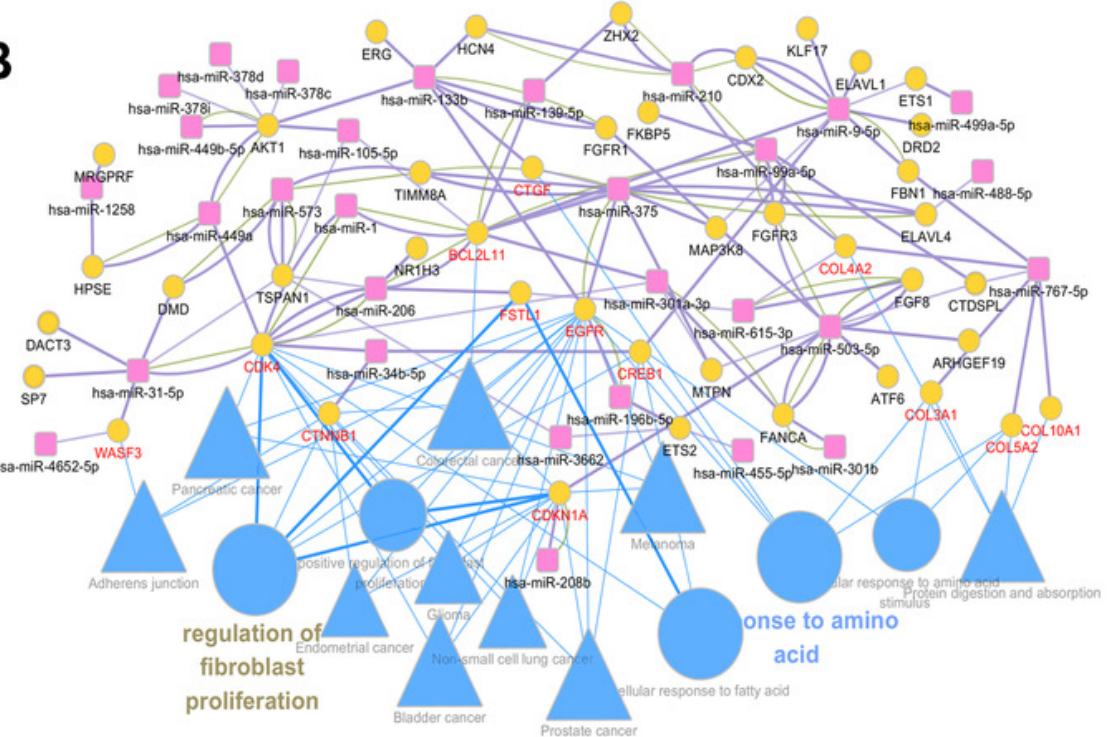

D

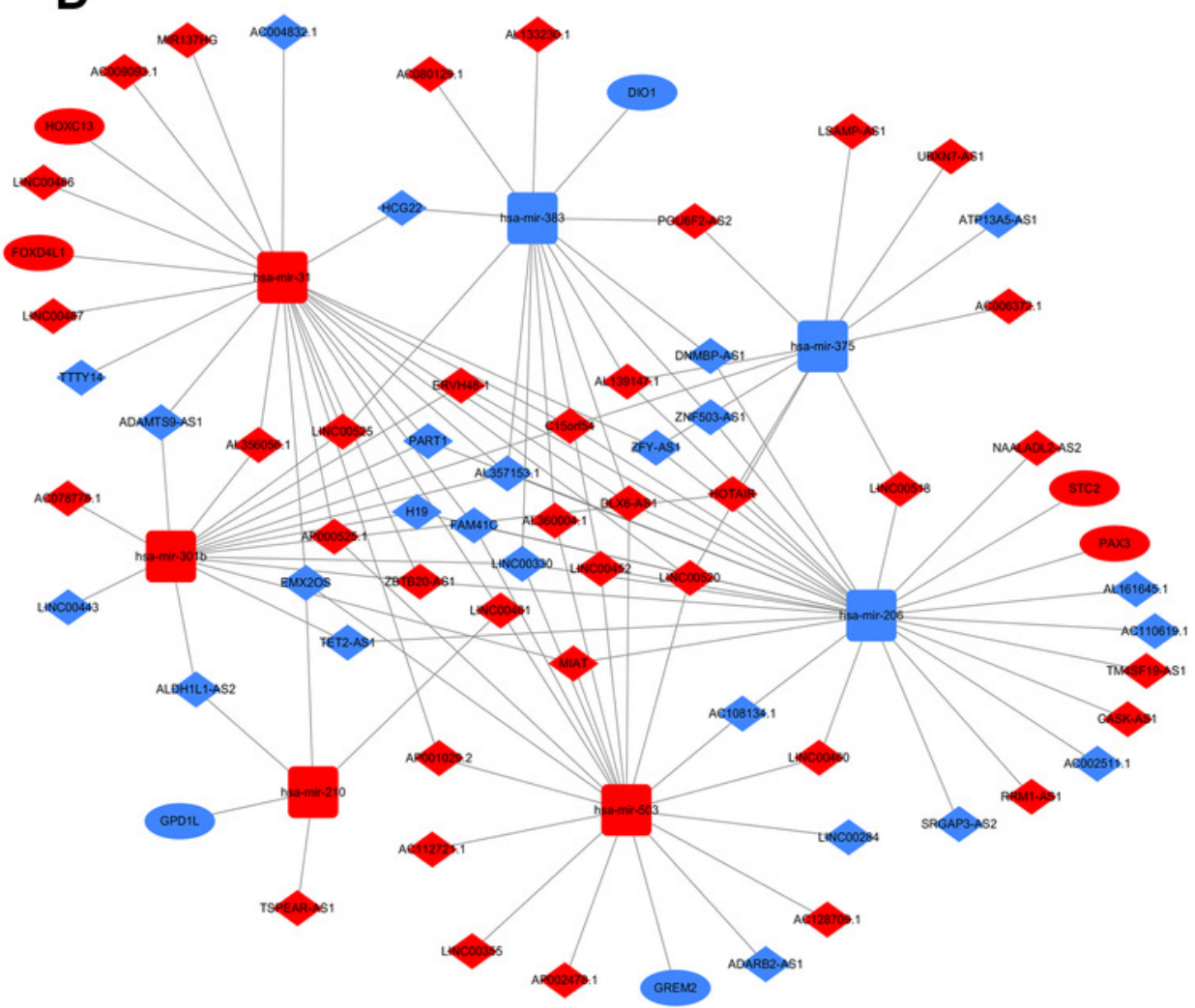




\section{Figure 4}

Figure 4. Function and survival analysis of RNAs in the ceRNA network

(A) Significant bioprocesses and (B) pathways representing the functions of mRNA in the ceRNA network. The horizontal axis stands for the number of enriched genes and the color intensity represents corrected P-value. Kaplan-Meier curves analysis of differentially expressed (C-G) IncRNAs, (H-K) mRNAs and (L) miRNA for the overall survival in LSCC patients. The horizontal axis represents overall survival time (years), while the vertical axis represents survival function.
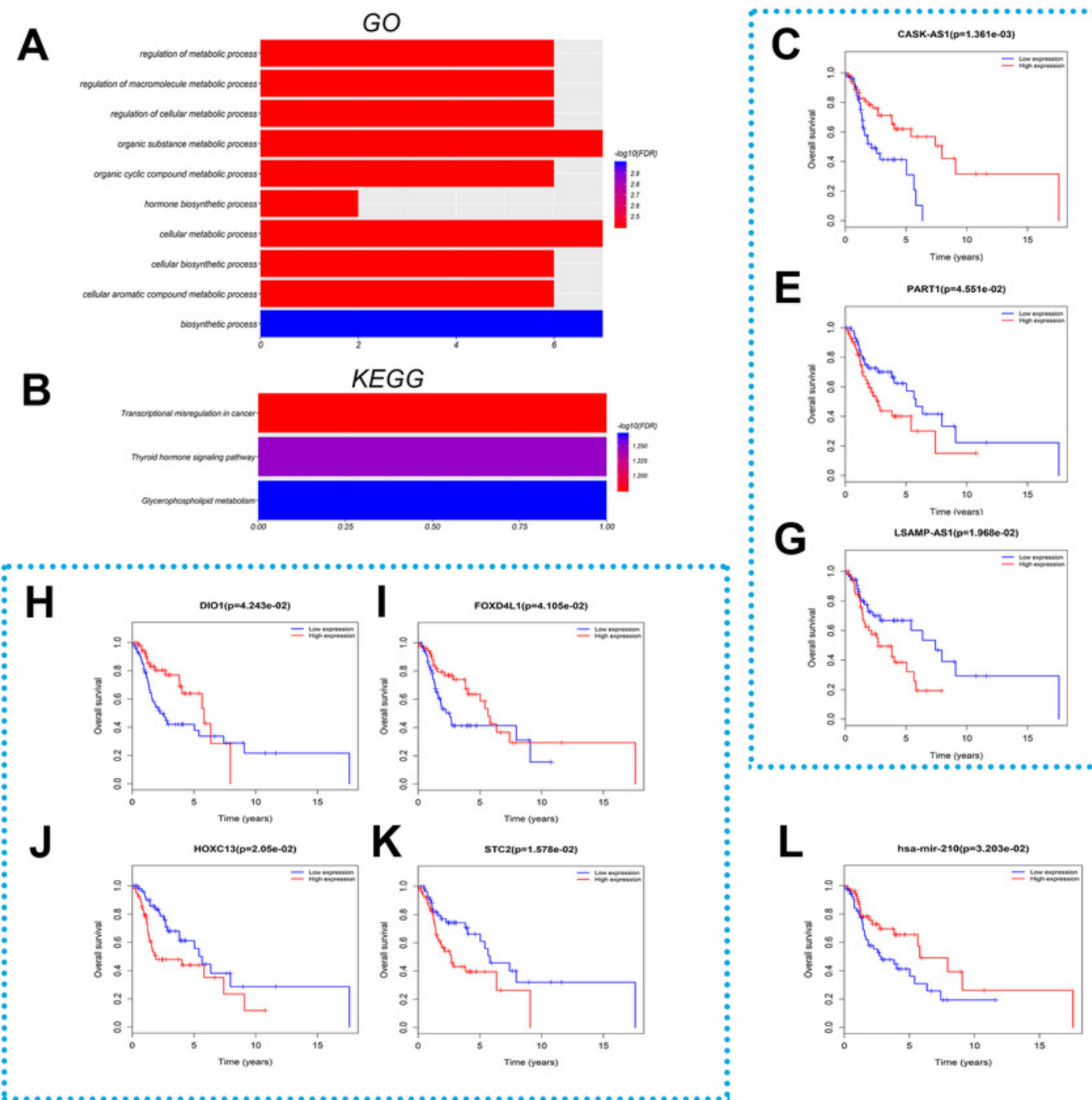
Table $\mathbf{1}$ (on next page)

Characteristics of patients 
1 Table 1. Characteristics of patients

\begin{tabular}{|c|c|c|}
\hline \multicolumn{2}{|l|}{ Characteristic } & \multirow[t]{2}{*}{ Number } \\
\hline Patient sex & & \\
\hline & Male & $97(82.9 \%)$ \\
\hline & Female & $20(17.1 \%)$ \\
\hline Patient age $(y) \quad(\bar{x} \pm S D)$ & & $61.9 \pm 9.1$ \\
\hline \multicolumn{3}{|l|}{ Tumor stage } \\
\hline & Stage I & $2(1.7 \%)$ \\
\hline & Stage II & $10(8.5 \%)$ \\
\hline & Stage III & $14(12.0 \%)$ \\
\hline & Stage IV & $74(63.2 \%)$ \\
\hline & unknow & $17(14.6 \%)$ \\
\hline \multicolumn{3}{|l|}{ T category } \\
\hline & $\mathrm{T} 1$ & $7(6.0 \%)$ \\
\hline & $\mathrm{T} 2$ & $14(12.0 \%)$ \\
\hline & T3 & $26(22.2 \%)$ \\
\hline & $\mathrm{T} 4$ & $55(27.0 \%)$ \\
\hline & unknow & $15(12.8 \%)$ \\
\hline \multicolumn{3}{|l|}{$\mathbf{N}$ category } \\
\hline & No & $41(35.0 \%)$ \\
\hline & $\mathrm{N} 1$ & $12(10.3 \%)$ \\
\hline & N2 & $41(35.0 \%)$ \\
\hline & N3 & $2(1.7 \%)$ \\
\hline & unknow & $21(18.0 \%)$ \\
\hline \multicolumn{3}{|l|}{ Vital status } \\
\hline & alive & $74(63.2 \%)$ \\
\hline & dead & $43(36.8 \%)$ \\
\hline
\end{tabular}


Table 2 (on next page)

The top 30 differentially expressed IncRNAs 
1 Table2. The top 30 differentially expressed IncRNAs

\begin{tabular}{|c|c|c|c|c|c|c|c|}
\hline IncRNA & $\log \mathrm{FC}$ & $\begin{array}{l}\text { Adjusted } \\
\text { P-value }\end{array}$ & Stage & IncRNA & $\log \mathrm{FC}$ & $\begin{array}{l}\text { Adjusted P- } \\
\text { value }\end{array}$ & Stage \\
\hline AC105460.1 & 9.624232519 & 3.47E-07 & up & LINC02303 & -8.124203643 & 4.01E-44 & down \\
\hline AC100801.1 & 8.238931778 & 1.93E-05 & up & LINC00314 & -6.70567849 & $6.54 \mathrm{E}-22$ & down \\
\hline AC010595.1 & 8.138849584 & 2.31E-14 & up & AL137246.2 & -6.665159808 & 1.29E-24 & down \\
\hline AC105460.2 & 7.716181392 & 8.04E-07 & up & SLC8A1-AS1 & -6.414996281 & $5.19 \mathrm{E}-106$ & down \\
\hline $\begin{array}{l}\text { MAGEA4- } \\
\text { AS1 }\end{array}$ & 7.494825221 & 0.0001893 & up & HCG22 & -6.335918315 & $3.33 E-43$ & down \\
\hline AC073365.1 & 7.389003818 & 4.59E-05 & up & LINC02487 & -5.798837862 & 4.01E-32 & down \\
\hline G2E3-AS1 & 7.222069873 & $1.00 \mathrm{E}-12$ & up & MIR133A1HG & -5.601245414 & $1.11 \mathrm{E}-17$ & down \\
\hline LINC02582 & 7.138114151 & 0.00068543 & up & LINC02538 & -5.578220186 & 5.78E-35 & down \\
\hline LINC02525 & 7.116487546 & 0.00448125 & up & LINC00330 & -5.497294479 & 2.86E-32 & down \\
\hline AC079062.1 & 7.047002194 & 0.00139717 & up & LINC00443 & -5.31185955 & 5.51E-26 & down \\
\hline AC087612.1 & 6.661860103 & 4.60E-07 & up & LINC01028 & -5.23325995 & 4.37E-18 & down \\
\hline LINC01194 & 6.617984821 & 0.00595607 & up & AC103563.2 & -5.187886248 & $2.52 \mathrm{E}-19$ & down \\
\hline & & 6 & & & & & \\
\hline
\end{tabular}




\begin{tabular}{|c|c|c|c|c|c|c|c|}
\hline AC022639.1 & 6.591725463 & 1.60E-05 & up & AC005532.1 & -5.074133501 & 1.77E-39 & down \\
\hline AFAP1-AS1 & 6.563017491 & 1.17E-06 & up & IL12A-AS1 & -5.062202771 & $1.56 \mathrm{E}-75$ & down \\
\hline AC092916.1 & 6.524150544 & 0.00879800 & up & LINC01765 & -5.013858116 & $1.85 \mathrm{E}-13$ & down \\
\hline & & 4 & & & & & \\
\hline
\end{tabular}

2 Notes:

3 Abbreviations: $\mathrm{FC}=$ fold change

4 
Table 3 (on next page)

The top30 differentially expressed mRNAs 
1 Table3.The top30 differentially expressed mRNAs

\begin{tabular}{|c|c|c|c|c|c|c|c|}
\hline mRNA & $\log \mathrm{FC}$ & $\begin{array}{l}\text { Adjusted } \\
\text { P-value }\end{array}$ & $\begin{array}{l}\text { Sta } \\
\text { ge }\end{array}$ & mRNA & $\log \mathrm{FC}$ & $\begin{array}{l}\text { Adjusted } \\
\text { P-value }\end{array}$ & Stage \\
\hline SOHLH1 & 10.25241617 & $1.23 \mathrm{E}-05$ & up & PRB4 & -9.884354737 & $4.80 \mathrm{E}-30$ & down \\
\hline MAGEA12 & 9.968586173 & 0.000146917 & up & $\begin{array}{l}\text { SCGB3 } \\
\text { A2 }\end{array}$ & -7.65197743 & 7.17E-44 & down \\
\hline MAGEA1 & 9.639662076 & 0.000247667 & up & PRB1 & -7.186135395 & 3.77E-20 & down \\
\hline MAGEC2 & 9.630175143 & 0.001526406 & up & MYH7 & -6.928426658 & $5.25 \mathrm{E}-21$ & down \\
\hline PAGE2 & 9.467661276 & 0.005362649 & up & $\begin{array}{l}\text { FBXO4 } \\
0\end{array}$ & -6.7579754 & $1.95 \mathrm{E}-29$ & down \\
\hline PRR20G & 8.976961309 & $5.75 \mathrm{E}-06$ & up & PYGM & -6.716881524 & $6.54 \mathrm{E}-36$ & down \\
\hline CTAG2 & 8.922913917 & 0.006038851 & up & KRT4 & -6.488075449 & $7.40 \mathrm{E}-30$ & down \\
\hline MAGEA3 & 8.79801806 & $6.40 \mathrm{E}-06$ & up & DWOR & -6.411014171 & $7.40 \mathrm{E}-16$ & down \\
\hline $\begin{array}{l}\text { ADAMTS2 } \\
0\end{array}$ & 8.728369712 & $3.35 \mathrm{E}-17$ & up & CRNN & -6.407039436 & 2.36E-25 & down \\
\hline LCE2B & 8.695652526 & 0.000497367 & up & $\begin{array}{l}\text { DHRS7 } \\
\text { C }\end{array}$ & -6.382622791 & 7.23E-23 & down \\
\hline SAGE1 & 8.660902318 & 0.000329428 & up & PIP & -6.36304819 & $1.53 \mathrm{E}-17$ & down \\
\hline MAGEA6 & 8.385660885 & 2.17E-05 & up & MYL3 & -6.334607727 & $2.82 E-29$ & down \\
\hline
\end{tabular}




\begin{tabular}{|l|l|l|l|l|l|l|l|}
\hline FGF19 & 8.234213225 & $9.44 \mathrm{E}-05$ & up & SMCO1 & -6.29838908 & $7.17 \mathrm{E}-51$ & down \\
\hline NOBOX & 8.171244913 & 0.002444398 & up & ASB11 & -6.111357822 & $3.61 \mathrm{E}-20$ & down \\
\hline CXorf67 & 8.083518872 & 0.005239453 & up & PRB3 & -6.04890691 & $2.37 \mathrm{E}-19$ & down \\
\hline
\end{tabular}

2 Notes:

3 Abbreviations: $\mathrm{FC}=$ fold change

4 
Table 4 (on next page)

The top30 differentially expressed miRNAs 
1 Table4.The top30 differentially expressed miRNAs

\begin{tabular}{|c|c|c|c|c|c|c|c|}
\hline miRNA & $\log \mathrm{FC}$ & $\begin{array}{l}\text { Adjusted } \\
\text { P-value }\end{array}$ & Stage & miRNA & $\log F C$ & $\begin{array}{l}\text { Adjusted } \\
\text { P-value }\end{array}$ & Stage \\
\hline $\begin{array}{l}\text { hsa-mir- } \\
105-2\end{array}$ & 6.46 & 0.000101469 & up & $\begin{array}{l}\text { hsa-mir- } \\
378 \mathrm{i}\end{array}$ & -4.98512 & $1.03 E-20$ & down \\
\hline $\begin{array}{l}\text { hsa-mir- } \\
105-1\end{array}$ & 6.23 & 8.60E-05 & up & $\begin{array}{l}\text { hsa-mir- } \\
1-1\end{array}$ & -4.12954 & 1.26E-09 & down \\
\hline $\begin{array}{l}\text { hsa-mir- } \\
767\end{array}$ & 6.17 & 4.09E-05 & up & $\begin{array}{l}\text { hsa-mir- } \\
208 b\end{array}$ & -4.1141 & 6.31E-07 & down \\
\hline $\begin{array}{l}\text { hsa-mir- } \\
\text { 1269b }\end{array}$ & 5.73 & 0.009537851 & up & $\begin{array}{l}\text { hsa-mir- } \\
1-2\end{array}$ & -4.10462 & $1.68 \mathrm{E}-09$ & down \\
\hline $\begin{array}{l}\text { hsa-mir- } \\
615\end{array}$ & 5.32 & $2.27 \mathrm{E}-10$ & up & $\begin{array}{l}\text { hsa-mir- } \\
\text { 133b }\end{array}$ & -3.90956 & $1.42 \mathrm{E}-07$ & down \\
\hline $\begin{array}{l}\text { hsa-mir- } \\
\text { 196a-2 }\end{array}$ & 4.87 & 9.52E-09 & up & $\begin{array}{l}\text { hsa-mir- } \\
\text { 133a-1 }\end{array}$ & -3.64194 & $1.42 \mathrm{E}-07$ & down \\
\hline $\begin{array}{l}\text { hsa-mir- } \\
\text { 196a-1 }\end{array}$ & 4.73 & 3.77E-08 & up & $\begin{array}{l}\text { hsa-mir- } \\
\text { 133a-2 }\end{array}$ & -3.55484 & 2.29E-07 & down \\
\hline $\begin{array}{l}\text { hsa-mir- } \\
\text { 514a-3 }\end{array}$ & 4.53 & 0.006426286 & up & $\begin{array}{l}\text { hsa-mir- } \\
\text { 449b }\end{array}$ & -3.47533 & 1.10E-06 & down \\
\hline hsa-mir- & & 0.00080213 & up & hsa-mir- & -3.36809 & $9.26 \mathrm{E}-13$ & down \\
\hline
\end{tabular}




\begin{tabular}{|c|c|c|c|c|c|c|c|}
\hline $548 f-1$ & 4.53 & & & 375 & & & \\
\hline $\begin{array}{l}\text { hsa-mir- } \\
\text { 514a-1 }\end{array}$ & 4.35 & 0.008651113 & up & $\begin{array}{l}\text { hsa-mir- } \\
449 a\end{array}$ & -3.22293 & 5.14E-08 & down \\
\hline $\begin{array}{l}\text { hsa-mir- } \\
9-3\end{array}$ & 4.10 & 2.62E-05 & up & $\begin{array}{l}\text { hsa-mir- } \\
\text { 378d-1 }\end{array}$ & -2.83308 & $5.25 \mathrm{E}-13$ & down \\
\hline $\begin{array}{l}\text { hsa-mir- } \\
9-2\end{array}$ & 4.07 & 2.71E-05 & up & $\begin{array}{l}\text { hsa-mir- } \\
\text { 378d-2 }\end{array}$ & -2.69707 & $3.01 \mathrm{E}-11$ & down \\
\hline $\begin{array}{l}\text { hsa-mir- } \\
9-1\end{array}$ & 4.07 & 2.71E-05 & up & $\begin{array}{l}\text { hsa-mir- } \\
\text { 499a }\end{array}$ & -2.57694 & 0.000641862 & down \\
\hline $\begin{array}{l}\text { hsa-mir- } \\
\text { 1269a }\end{array}$ & 4.01 & 0.00052332 & up & $\begin{array}{l}\text { hsa-mir- } \\
206\end{array}$ & -2.44746 & 0.003311076 & down \\
\hline $\begin{array}{l}\text { hsa-mir- } \\
1910\end{array}$ & 3.85 & 6.34E-09 & up & $\begin{array}{l}\text { hsa-mir- } \\
6510\end{array}$ & -2.39858 & $6.35 \mathrm{E}-08$ & down \\
\hline
\end{tabular}

2 Notes:

3 Abbreviations: $\mathrm{FC}=$ fold change

4 


\section{Table 5 (on next page)}

The differentially expressed IncRNAs, miRNAs, and mRNAs included in ceRNA network 
1 Table4.The target genes of miRNAs in ceRNA network based on databases

\begin{tabular}{|c|c|c|c|c|}
\hline miRNA & LogFC & $\begin{array}{l}\text { Adjusted } \\
\text { P-value }\end{array}$ & Stage & Target genes \\
\hline hsa-mir-210 & 2.298119 & 1.05E-05 & up & $\begin{array}{l}\text { SH3BGRL,ALDH5A1,DENND6A,POU2AF1,SERTM1,V } \\
\text { AMP4,FGFRL1,GPD1L,AIFM3,ACVR1,BKCMF1,ISCU, } \\
\text { SIN3A,MDGA1, }\end{array}$ \\
\hline hsa-mir-375 & -3.368088771 & $9.26 \mathrm{E}-13$ & down & RLF,ELAVL4 \\
\hline hsa-mir-206 & -2.44746455 & 0.003311076 & down & $\begin{array}{l}\text { WEE1,EIF1AX,FRS2,PGD,FNDC3A,KCNJ2,G6PD,STC } \\
\text { 2,GPD2,PAX3,ZNF215,LRRC59,TKT,BDNF,BSCL2,GJ } \\
\text { A1,VAMP2, } \\
\text { ANP32B,SFRP1,HSP90B1,KRAS,MATR3,CERS2,RNF } \\
\text { 138,SMARCB1,UTRN,NUP50 }\end{array}$ \\
\hline hsa-mir-383 & -2.376630995 & 0.001185218 & down & DIO1,SRSF2,VEGFA,ADSS,IRF1 \\
\hline hsa-mir-31 & 3.292738762 & 0.006118236 & up & $\begin{array}{l}\text { TBXA2R,STK40,MZT1,ZNF805,SELE,FOXD4,FZD3,FO } \\
\text { XD4L5, } \\
\text { SP1,FOXD4L4,ZC3H12C,FOXD4L1,LATS2,SYDE2,PR } \\
\text { KCE,RHOBTB1,HIF1AN,RASA1,ARID1A,GTF2E1,NOL } \\
\text { 9,HOXC13,JAZF1,CCNT1,C19orf12,ECHDC1,NF2,NU } \\
\text { MB,ARF1,PPP2R2A,PARP1,ABCB9,YWHAE,KLF13 }\end{array}$ \\
\hline hsa-mir-503 & 2.371556173 & 1.88E-07 & up & RALGAPB,CREBL2,CCND2,CCND1,GREM2,JARID2,Z \\
\hline
\end{tabular}




\begin{tabular}{|l|l|l|l|l|}
\hline & & & & NF282,ZNRF2 \\
\hline hsa-mir-301b & 2.864323582 & $8.75 \mathrm{E}-07$ & up & - \\
\hline
\end{tabular}

2 Notes:

3 Abbreviations: $\mathrm{FC}=$ fold change 
Table 6(on next page)

The target genes of miRNAs in ceRNA network based on databases 
1 Table5. The differentially expressed IncRNAs, miRNAs, and mRNAs included in ceRNA network

\begin{tabular}{|c|c|}
\hline $\begin{array}{l}\text { The type } \\
\text { of RNAs }\end{array}$ & Gene symbols \\
\hline LncRNA & $\begin{array}{l}\text { H19,LINC00525,PART1,C15orf54,AL357153.1,TTTY14,AP002478.1,LINC } \\
\text { 00518,AC009093.1, } \\
\text { AL360004.1, AC004832.1,ADARB2- } \\
\text { AS1,AC002511.1,LINC00487,AC108134.1,AP000525.1, MIAT,UBXN7- } \\
\text { AS1,ZNF503-AS1,NAALADL2-AS2,LINC00355,DNMBP- } \\
\text { AS1,HOTAIR,SRGAP3-AS2,HCG22, } \\
\text { LINC00452,EMX2OS,LINC00443,FAM41C,AL161645.1,LINC00486,MIR13 } \\
\text { 7HG,DLX6-AS1,CASK-AS1,ERVH48-1,ZFY- } \\
\text { AS1,LINC00460,LINC00284,POU6F2-AS2,LINC00330,TSPEAR- } \\
\text { AS1,TM4SF19-AS1,ATP13A5- } \\
\text { AS1,AC006372.1,AC112721.1,AL133230.1,AC080129.1, } \\
\text { AL356056.1,LSAMP-AS1, ADAMTS9-AS1,ZBTB20- } \\
\text { AS1,AC078778.1,LINC00461,ALDH1L1-AS2,AL139147.1,AC128709.1, } \\
\text { AS1,RRM1-AS1,AC110619.1,AP001029.2,LINC00520 }\end{array}$ \\
\hline MiRNA & $\begin{array}{l}\text { hsa-mir-301b,hsa-mir-206,hsa-mir-31,hsa-mir-383, hsa-mir-375, hsa-mir- } \\
\text { 503,hsa-mir-210 }\end{array}$ \\
\hline mRNA & GPD1L,GREM2,HOXC13,STC2,DIO1,FOXD4L1,PAX3 \\
\hline
\end{tabular}

